\title{
O Fórum dos Coordenadores do Programa Institucional de Bolsa de Iniciação à Docência no contexto de luta pela valorização dos professores da educação básica
}

\author{
ASSIS, Alessandra ${ }^{1}$ \\ SILVA, Jaqueline Barbosa $d a^{2}$
}

\begin{abstract}
RESUMO
Este artigo intenciona socializar a trajetória do Fórum dos Coordenadores do PIBID (FORPIBID), enfatizando o percurso histórico do Programa no âmbito nacional. O diálogo paritário entre docentes e discentes, da Educação Básica e do Ensino Superior, evidencia o processo aprendente e ensinante que tem impulsionado a relação entre o FORPIBID, os órgãos financiadores e a rede interinstitucional de instituições de Ensino Superior brasileiras, consolidando a luta pela permanência e aperfeiçoamento do programa, bem como sua organicidade em relação a outros programas voltados para a valorização da formação de professores para a Educação Básica, a exemplo do PARFOR, LIFE, PRODOCÉNCIA, NOVOS TALENTOS, PNAIC.
\end{abstract}

FORPIBID. PIBID Diversidade. Educação Básica. Ensino Superior.

\begin{abstract}
This article intends to socialize the trajectory of the Fórum dos Coordenadores do PIBID (PIBID Coordinators Forum - FORPIBID), emphasizing the historical way of the program in the national scope. The dialogue between peers of the teachers and students, from the basic education and the higher education, evidences the learning and teaching process that has boosted the relation between the FORPIBID, the financiers agencies and the inter institutional net of the Brazilians high education institutions, consolidating the fight for the permanence and the improvement of the program, as well as its organization concerning the other programs direct toward the appreciation of the teachers

\footnotetext{
${ }^{1}$ Doutora e Mestre em Educação pela Universidade Federal da Bahia (UFBA). Licenciada em Pedagogia pela UFBA. Atualmente é professora do Departamento de Educação II da Faculdade de Educação da UFBA, onde leciona na graduação e na pós-graduação, desenvolve pesquisas e atividades de extensão. Tem experiência na área de Educação e Práticas Docentes, Didática, Educação à Distância e Tecnologias na Educação. E-mail: bralessandra2007@gmail.com

${ }^{2}$ Doutora e Mestre em Educação pela Universidade Federal de Pernambuco (UFPE). Licenciada em Pedagogia pela UFPE. Atualmente é professora do Núcleo de Formação Docente do Centro Acadêmico do Agreste da UFPE, onde exerce a docência, a extensão e a pesquisa. Tem experiência na área de Educação, com ênfase em política educacional e formação de professores, atuando principalmente nos seguintes temas: Educação do Campo, Prática Educativa, Educação Popular, Movimentos Sociais e (Auto)Biografias-Narrativas. Email: jaqueline.barbosa@yahoo.com.br
} 
education to the basic education, as it has been seen in PARFOR, LIFE, PRODOCÉNCIA, NOVOS TALENTOS, PNAIC.

FORPIBID. PIBID Diversidade. Basic Education. Higher Education.

\section{INTRODUÇÃO}

O Programa Institucional de Bolsa de Iniciação à Docência (PIBID) e o Programa Institucional de Bolsa de Iniciação à Docência para a Diversidade (PIBID Diversidade), enquanto política pública de formação de professores, marcou a história das licenciaturas no Brasil. Mesmo sob o efeito de avanços e retrocessos no contexto de disputa por um projeto nacional de formação de professores para escolas públicas, o programa segue atendendo às populações do campo e da cidade, comunidades indígenas e quilombolas, resistindo e mobilizando educadores e incentivando a formação de novos profissionais da educação. O movimento de defesa do programa, organizado pelo Fórum Nacional de Coordenadores do PIBID e PIBID Diversidade (FORPIBID) é continuamente ampliado e renovado, qualificando o debate sobre que professores queremos formar para transformar a realidade educacional brasileira.

Nesse texto, discutimos a origem do programa, seus desafios atuais, o papel do Fórum e a importância do movimento em defesa do PIBID. Com isso, a expectativa é informar e, ao mesmo tempo, contribuir para o debate acerca do processo de valorização da formação de professores, elemento central das mudanças educacionais que almejamos para o país. Acreditamos que juntos somos muitos e somos fortes, frente ao desafio de fortalecer a luta contínua pela dignidade dos profissionais da educação que atuam nos diferentes territórios e nos mais diversos espaços de ensino-e-aprendizagem.

\section{Origem e trajeto do Pibid}

O crescimento desses programas, PIBID e PIBID Diversidade, desde sua criação - PIBID em 2007 e PIBID Diversidade em 2010, provocou mudanças no âmbito da formação de professores, impactando a dinâmica da Educação Básica nas regiões brasileiras.

Quando o PIBID foi concebido pela CAPES/Ministério da Educação, em 2007, foi um destaque no âmbito das ações governamentais. Seu crescimento foi exponencial, ao destinar bolsas para estudantes das licenciaturas, professores da educação básica, e professores das Instituições de Ensino Superior (IES), visando uma formação docente desenvolvida a partir da 
realidade das escolas públicas. Seu alcance passou a ser referência no campo das políticas públicas educacionais, indicando outra concepção de formação docente. A dicotomia entre teoria e prática foi superada com a aproximação entre IES e escolas da Educação Básica, vinculando profissão docente e formação docente, valorizando a produção de conhecimento por meio da experiência do professor.

Em 2010, o PIBID Diversidade entrou em cena, contemplando os povos indígenas, do campo, quilombolas e ribeirinhos, através do Edital Conjunto № 002/2010/CAPES/SECADI-MEC, contemplando 21 IES $^{3}$.

Em 2016, o programa, incluindo o público do PIBID e PIBID Diversidade, contemplou 90.254 bolsistas de Iniciação à Docência, de Supervisão e de Coordenação ${ }^{4}$, em 284 Instituições de Educação Superior, com 313 projetos em 5.898 escolas da Educação Básica do campo, em territórios indígenas e quilombolas, bem como nas pequenas e grandes cidades. Segundo relatório de impacto do PIBID, os programas PIBID e PIBID Diversidade beneficiou cerca de 170 mil licenciandos, 20 mil professores da Educação Básica e nove mil professores das instituições formadoras.

Para além desses números, o PIBID tem demonstrado a importância de fortalecer cada vez mais o diálogo entre as IES e a Educação Básica. Os projetos ao contar com ações, práticas pedagógicas inovadoras, feiras, exposições, produção de materiais pedagógicos, ampliação de repertório cultural, investigações do cotidiano da prática docente e inúmeras publicações têm criado um movimento inovador, crítico e propositivo na formação inicial e continuada de professores.

Assim, o PIBID e o PIBID Diversidade ganharam espaço, destacando-se pela permanência dos licenciandos no ensino superior; na vivência com as

\footnotetext{
${ }^{3}$ Entre as instituições que submeteram projeto ao Edital Conjunto № 002/2010/CAPES/SECAD-MEC foram contemplados o Centro de Ensino Superior de Arcoverde (CESA), o Centro de Ensino Superior do Vale do São Francisco (CESVASF), o Instituto Superior de Educação Professor Aldo Muylaert (ISEPAM), o Instituto Federal de Educação, Ciência e Tecnologia da Bahia (IFBA), a Universidade Federal do Amazonas (UFAM), a Universidade Federal da Bahia (UFBA), a Universidade Federal do Ceará (UFC), a Universidade Federal de Goiás (UFG), a Universidade Federal da Grande Dourados (UFGD), a Universidade Federal de Minas Gerais (UFMG), a Universidade Federal de Pernambuco (UFPE), a Universidade Federal do Piauí (UFPI), a Universidade Federal de Roraima (UFRR), a Universidade Federal de Santa Catarina (UFSC), a Universidade Federal dos Vales do Jequitinhonha e Mucuri (UFVJM), a Universidade de Brasília (UnB), a Universidade Estadual do Mato Grosso (UNEMAT), a Universidade Estadual do Centro-Oeste (UNICENTRO), a Universidade Federal de Rondônia (UNIR), a Universidade de Taubaté (UNITAU) e a Universidade Tecnológica Federal do Paraná (UTFPR), grifo do autor.

${ }^{4}$ Sendo 87.060 bolsistas vinculados ao Pibid e 3.194 pertencente ao Pibid Diversidade, conforme dados da Capes, disponível em: <https://www.capes.gov.br/educacaobasica/capespibid/relatorios-e-dados>, consultado em 08 junho de 2018.
} 
comunidades escolares, sob a supervisão de professores que integram 0 Programa; no reconhecimento do professor da Educação Básica como coformador; no compartilhamento de práticas formativas nas diversas áreas de conhecimento; na interlocução das IES com as escolas e as comunidades; na motivação dos estudantes da Educação Básica na continuidade da escolarização; na ampliação dos espaços de discussão sobre as práticas docentes e sobre as licenciaturas nas IES; no desenvolvimento de práticas educativas afirmativas pautadas pela diferença; na sinergia entre os demais programas da CAPES, a exemplo do Programa Nacional de Formação de Professores da Educação Básica (PARFOR), Programa de Apoio aos Laboratórios Interdisciplinares de Formação de Educadores (Life), Programa de Consolidação das Licenciaturas (PRODOCÊNCIA), Novos Talentos, Programa Nacional de Alfabetização pela Idade Certa (PNAIC); na apropriação criativa das tecnologias digitais da informação e comunicação; e, no desenvolvimento de projetos e práticas interdisciplinares.

Nesse contexto, as experiências formativas plenamente qualificadas ampliaram-se e intensificaram-se, reforçando o diálogo das escolas com as IES. Assim, mais que um programa de bolsas, o PIBID constituiu-se em Política Pública de Formação de Professores, construída coletivamente, posta como um compromisso do Estado Brasileiro, assegurado pela Lei de Diretrizes e Bases da Educação Nacional (Lei 9.394/96) e pelo disposto na Lei 12.796 de 04 de abril de 2013, em consonância com as metas do Plano Nacional de Educação (Lei 13.005/14) para o decênio 2014-2024.

\section{O Forpibid e a valorização da formação de professores}

O FORPIBID surgiu no contexto de valorização da formação dos professores e se consolidou politicamente diante da precarização que evoluiu para risco de descontinuidade do programa, a despeito dos excelentes resultados alcançados, ano a ano. Mesmo antes da criação oficial do Fórum, e desde a origem do programa, marcado pela gestão democrática, ocorria uma intensa articulação entre os coordenadores institucionais do PIBID. Encontros nacionais de coordenadores foram organizados periodicamente pela CAPES, com o objetivo de avaliar o andamento das ações, compartilhar experiências e definir os próximos passos do programa, no âmbito federal e institucional. Essa dinâmica oportunizou também, a organização política dos coordenadores. Em paralelo, o Fórum Nacional de Pró-Reitores de Graduação (FORGRAD) instituiu o Encontro Nacional das Licenciaturas (ENALIC) integrado ao Seminário Nacional do Pibid, dando início a uma série de eventos para os quais foi, e continua sendo usado, o espaço de encontro e troca de 
experiências. Este vem sendo, paulatinamente, ocupado pelos membros dos programa - PIBID e PIBID Diversidade.

Em 2013, durante a realização do IV Encontro Nacional das Licenciaturas e III Seminário Nacional do PIBID, em Uberaba/MG, com participação expressiva de coordenadores do PIBID, ocorreu a instalação da Comissão Nacional para Criação do FORPIBID. Composta por representantes das cinco regiões do país, escolhidos em sessão plenária, a Comissão teve o prazo de um ano para a elaboração do regimento, que fora apresentado no evento do ano seguinte. A Comissão teve como ponto de partida as discussões realizadas em grupos de trabalho por região, que sinalizaram na plenária final, as expectativas dos coordenadores acerca dos objetivos, composição e modo de funcionamento do Fórum.

Em 2014, durante o V Encontro Nacional das Licenciaturas e IV Seminário Nacional do PIBID, realizado em Natal/RN, foi realizada a primeira Assembleia de Coordenadores Institucionais do PIBID para a discussão e aprovação do Regimento do FORPIBID e eleição da primeira diretoria do Fórum. A estrutura organizacional do Fórum, a começar pela escolha dos coordenadores que representariam nacionalmente o coletivo, configurava-se de modo horizontal, descentralizado e dinâmico, com a participação dos coordenadores das cinco regiões do país e vinculados à diferentes instâncias administrativas das IES, caracterizando-se pelas especificidades dos programas, de modo geral e específico. O fluxo de discussão e tomada de decisões obedecia a análise de demandas por coordenações regionais e estaduais, gerando um processo qualificado de reflexão acerca das demandas postas ao Fórum. Assim, o FORPIBID passou a funcionar como legitimado porta-voz dos membros envolvidos, buscando sistematizar informações e apresentar posições das IES frente à CAPES e outros interlocutores, contribuindo para a efetiva manutenção do PIBID e para o aperfeiçoamento do trabalho em cada instituição, ajudando a aprimorar os diversos aspectos da política pública.

O FORPIBID, constituído no diálogo entre sujeitos do PIBID e do PIBID Diversidade, rompeu com a linearidade colonialista das ações societárias e governamentais. Nesta direção, os sujeitos aprendentes substituíram a leitura das condições de vida de subalternizados por posturas auto afirmativas em relação à história local e à identidade indígena, do campo e quilombola.

O planejamento, o acompanhamento, os encaminhamentos e a sistematização das ações suscitaram a articulação entre o PIBID e o PIBID Diversidade com a rede de formação de professores, em nível nacional e local. Em nível nacional os programas contaram com 0 apoio financeiro da Coordenação de Aperfeiçoamento de Pessoal de Nível Superior (CAPES), o 
incentivo da Secretaria de Educação Continuada, Alfabetização, Diversidade e Inclusão (SECADI), da Associação Brasileira dos Reitores das Universidades Estaduais e Municipais (ABRUEM), da União Nacional dos Dirigentes Municipais de Educação (UNDIME), da Federação de Sindicatos de Professores e Professoras de Instituições Federais de Ensino Superior e de Ensino Básico Técnico e Tecnológico (PROIFES).

Nos Estados, o FORPIBID conta com os Programas de Formação de Professores, as Secretarias de Educação, as Fundações de Pesquisa, os Centros de Estudos e Pesquisas, as Comissões de Professores Indígenas, os Fóruns de Educação e os Movimentos Sociais do Campo, Indígenas e Quilombolas.

Assim, a evidência às autoidentidades e a organização político-cultural do Fórum alia-se às demandas dos sujeitos envolvidos nos programas explicitando a luta pela valorização da formação dos professores da Educação Básica, bem como evidencia a luta dos sujeitos historicamente silenciados numa dinâmica de compartilhamento das aprendizagens próprias dos grupos envolvidos.

A dinâmica de trabalho do FORPIBID inclui, entre outras: reuniões virtuais com os coordenadores dos programas - PIBID e PIBID Diversidade, através de web conferências; encontros regionais e nacionais; mobilizações em defesa da educação pública e da valorização dos profissionais da educação; audiências na câmara e no senado federal; visita nos gabinetes dos deputados e senadores; reunião com a CAPES, SECADI e MEC.

Esse conjunto de ações tem como instrumento de registro o boletim informativo, sistematizado, debatido e divulgado para atualização dos participantes dos programas, na medida em que as atividades são realizadas e concluídas.

O diálogo paritário, entre os membros gestores - presidente, vicepresidente, secretaria, tesouraria e representante do PIBID Diversidade, subsidia o trabalho do Fórum, propiciando uma atenção pormenorizada aos novos desenhos conjunturais que vislumbram-se diante das mudanças de gestão da CAPES e/ou governo. Este caminho de construção é elaborado coletivamente, atendendo ao chamado das coordenações institucionais, particularmente em se tratando das diferenças e especificidades contextuais.

Assim, a articulação entre as diferentes IES, as escolas e a integração dos sujeitos permitem outros formatos relacionais, outros modos de fazer a Educação Básica e, sobremaneira, construir novas identidades para o processo formativo do Ensino Superior à medida que os participantes atualizam o processo formativo, possibilitando outras leituras de mundo. 
3 Por uma educação libertadora: o PIBID Diversidade no contexto de luta do FORPIBID

Desde a constituição do Estado brasileiro, em 1822, as elites nativas brancas, latifundiárias e empresariais, sempre que tiveram seus interesses contrariados, nunca hesitaram em romper a ordem institucional para protegêlos. Por essa razão, nosso país esteve submetido a sucessivos golpes de Estado, podendo chegar até uma dezena se considerarmos aqueles deflagrados dentro da suposta ordem institucional-legal, a exemplo do último que resultou no afastamento da presidenta Dilma Rousseff. Independentemente de se tratar de golpe civil, militar ou civil-militar, todos eles possuem uma mesma característica, golpe é golpe. Por isso, após a realização de um golpe, por mais disfarçado que seja, vem sempre o regime de Exceção, foi sempre assim e é assim que está sendo agora nesse momento pós-golpe aqui no Brasil.

No regime de exceção, não se pode criticar, questionar, fazer reunião, promover debates etc. Foi por esse motivo que, antes do golpe, em preparação ao golpe, começou a tramitar na Câmara Federal o Projeto de Lei no 867/2015, que pretende inserir entre as diretrizes e bases da educação nacional 0 Programa Escola sem Partido. Trata-se de uma iniciativa para calar a voz de estudantes e professores, impedindo qualquer manifestação crítica dos mesmos.

Com o golpe efetivado, reafirma-se o lugar de poder dos órgãos governamentais, procedendo à descontinuidade do PIBID Diversidade no Edital $N^{\circ} 07$ de 2018, da CAPES, quando, na tentativa de não invisibilizar os sujeitos contemplados nos projetos das áreas intercultural indígena e educação do campo, passa a contemplar como instituições e cursos elegíveis as licenciaturas Intercultural Indígena e Educação do Campo, desde que esteja "[...] devidamente cadastrado no sistema e-MEC na situação "em atividade". (CAPES, Edital No 7, Item $4.2 \S$ III, 2018).

$\mathrm{O}$ atendimento a essa exigência, no caso dos programas voltados para a formação de professores do campo e indígena, expressa alguns retrocessos, entre eles: (1) a não consolidação das referidas licenciaturas, permanecendo, na maioria das IES, na condição de programa, com tempo de duração programado; (2) a descontinuidade das ações que vinham sendo desencadeadas pelo conjunto das IES contempladas no âmbito do PIBID Diversidade. 
A política de descentralização das instituições públicas de Ensino Superior no País, com a oferta de diferentes cursos, dentre esses as licenciaturas Interculturais Indígenas e Educação do Campo, respondem ao anseio nacional pelo direito a Educação que se materializa no acesso das populações historicamente excluídas do Ensino Superior, e principalmente da permanência na universidade dos povos indígenas, do campo e quilombolas.

Nesse cenário, o FORPIBID aproxima-se dos discursos em prol das diferenças, pautando o debate no hall de suas lutas, mobilizando, por um lado, os coordenadores do PIBID Diversidade, através da representação da coordenação eleita em assembleia nacional, e, por outro lado, intensificando o diálogo com as instâncias gestoras e representativas do programa. Dentro desse panorama mais geral, a luta do público da diversidade adquire notoriedade e passa, na medida do possível, a figurar mais explicitamente no debate em nível nacional.

Assim, o público do PIBID e do PIBID Diversidade passa a fazer-se presente na aproximação entre as Secretarias de Educação, as IES e as Escolas de Educação Básica, conjugando ensino, pesquisa e extensão por meio de ações de intervenção nas escolas das redes públicas - estaduais e municipais - e nos espaços educativos dos Movimentos Sociais do Campo e das cidades, dos Centros de Formação em Alternância, atuação fortalecida com a efetivação do PIBID Diversidade.

$\mathrm{Na}$ contramão destes avanços, o Edital $\mathrm{N}^{\circ} 07$ de 2018, publicado pela CAPES, desconsidera o caráter específico e diferenciado do público do campo, quilombola e indígena, infringindo a Convenção 169 quanto ao processo de formação de docentes nestes territórios e a Lei $N^{\circ} 12.796$ de 2013, que altera 0 texto da LDB, incluindo o PIBID como incentivo a formação docente,

$\S 5^{\circ}$ A União, o Distrito Federal, os Estados e os Municípios incentivarão a formação de profissionais do magistério para atuar na educação básica pública mediante programa institucional de bolsa de iniciação à docência a estudantes matriculados em cursos de licenciatura, de graduação plena, nas instituições de educação superior. (BRASIL, 2013).

O reconhecimento do PIBID, enquanto programa de iniciação à docência anuncia a relevância social da formação docente e seu caráter inovador na formação dos futuros professores brasileiros, ampliando os conhecimentos daqueles que já encontram-se atuando no âmbito da educação escolar indígena, quilombola e do campo. 
Outrossim, preconiza a atenção, a prioridade e o apoio permanente dos gestores de políticas educacionais, no sentido de que sejam garantidas as condições materiais e pedagógicas para o desenvolvimento das ações do PIBID. E as universidades públicas continuam constituindo-se o lócus da gestão de programas de formação inicial dos docentes sob a gestão da CAPES.

As alterações dos princípios e da operacionalização do PIBID Diversidade representa um retrocesso quando (1) interrompe os projetos em andamento nas Instituições de Ensino Superior, (2) limita o processo de formação na iniciação à docência ao trabalho de reforço escolar, (3) reafirma o privilégio de áreas de conhecimento clássicas na Educação; bem como, (4) exclui a possibilidade de participação das licenciaturas que, até a data limite de submissão da proposta, não tenha passado pelo processo seletivo de abertura de novas turmas.

A resistência do FORPIBID é expressa na defesa da educação escolar indígena, quilombola e do campo diante dos órgãos legisladores e financiadores do PIBID Diversidade, visando manter o fortalecimento da educação própria e diferenciada através das ações que acentuam o princípio do trabalho com as diferenças.

Para atender esta proposição, ao longo de oito anos de existência (2010-2018), o PIBID Diversidade ao integrar o Ensino Superior ao Ensino Básico, buscou estreitar os distanciamentos entre a comunidade, universidade, escola, o FORPIBID, a CAPES e a SECADI, embora nem sempre essa aproximação tenha gerado resultados satisfatórios.

A condição da diferença nem sempre se afirma diante das forças e das regras aos poderes, reduzindo-nos a meros executores de ações. As lutas contra a privacidade de existência dos desiguais produzem rebeldia e criatividade social pela existência livre e construção própria do movimento que faz gerar as ações. Essas atitudes, que emergem frente à indignação, materializam-se em posicionamentos criativos e superadores dos apelos sóciopolíticos e pressões externas.

Porém, não podemos negar o legado da existência do PIBID Diversidade, quando, no Edital $\mathrm{N}^{\circ} 66 / 2013$, chegou a contemplar 29 Instituições de Ensino Superior (IES), distribuídas nas cinco regiões brasileiras, conforme quadro 1. 
O Fórum dos Coordenadores do Programa Institucional de Bolsa de Iniciação à Docência no contexto de luta pela valorização dos professores da educação básica

Quadro 1 - Instituições contempladas pelo Pibid Diversidade - 2013

\begin{tabular}{|c|c|c|}
\hline Região & Estado & IES \\
\hline \multirow{10}{*}{ Nordeste } & Pernambuco & Universidade Federal de Pernambuco \\
\hline & \multirow{3}{*}{ Bahia } & Universidade Estadual da Bahia \\
\hline & & Instituto Federal da Bahia \\
\hline & & Universidade Federal do Recôncavo Baiano \\
\hline & \multirow[t]{2}{*}{ Ceará } & Universidade Regional do Cariri \\
\hline & & Universidade Federal do Ceará \\
\hline & Piauí & Universidade Federal do Piauí \\
\hline & Paraíba & Universidade Federal de Campina Grande \\
\hline & \multirow[b]{2}{*}{ Maranhão } & Universidade Federal do Maranhão \\
\hline & & Instituto Federal do Maranhão \\
\hline \multirow{5}{*}{ Sul } & \multirow{3}{*}{ Paraná } & Universidade Tecnológica Federal do Paraná \\
\hline & & Universidade Estadual de Maringá \\
\hline & & Universidade Estadual do Oeste do Paraná \\
\hline & \multirow{2}{*}{$\begin{array}{c}\text { Santa } \\
\text { Catarina }\end{array}$} & $\begin{array}{l}\text { Universidade Federal de Santa Catarina } \\
\text { Universidade Federal da Fronteira Sul }\end{array}$ \\
\hline & & 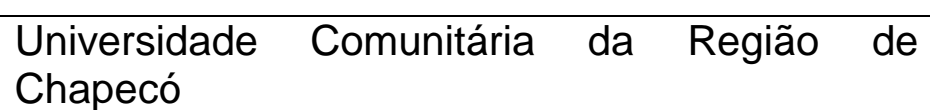 \\
\hline \multirow[b]{5}{*}{ Norte } & \multirow{2}{*}{ Pará } & $\begin{array}{l}\text { Instituto Federal de Educação, Ciência e } \\
\text { Tecnologia do Pará }\end{array}$ \\
\hline & & Universidade Federal do Pará \\
\hline & Amazonas & Universidade Federal do Amazonas \\
\hline & Rondônia & Universidade Federal de Rondônia \\
\hline & Roraima & Universidade Federal de Roraima \\
\hline \multirow{4}{*}{$\begin{array}{l}\text { Centro- } \\
\text { Oeste }\end{array}$} & Goiás & $\begin{array}{l}\text { Universidade Federal de Goiás } \\
\text { Universidade Federal de Grande Dourados }\end{array}$ \\
\hline & Mato Grosso & Universidade do Estado de Mato Grosso \\
\hline & do Sul & Universidade Federal de Mato Grosso do Sul \\
\hline & $\begin{array}{l}\text { Distrito } \\
\text { Federal }\end{array}$ & Universidade de Brasília \\
\hline \multirow[b]{2}{*}{ Sudeste } & São Paulo & Universidade de Taubaté \\
\hline & & $\begin{array}{l}\text { Universidade Federal de Minas Gerais } \\
\text { Universidade Federal }\end{array}$ \\
\hline
\end{tabular}




\begin{tabular}{|l|l|l|}
\hline & Minas Gerais & Jequitinhonha e Mucuri \\
\hline
\end{tabular}

Fonte: CAPES/2013.

O quadro revela que as regiões nordeste e sul totalizam $55 \%$ das IES contempladas com o PIBID Diversidade, restando as três demais regiões, norte, centro-oeste e sudeste, os $45 \%$ da oferta.

No conjunto das 29 IES, o PIBID Diversidade esteve representado através dos cursos voltados para o atendimento das populações indígenas e do campo, contemplando 33 projetos, conforme quadro 2.

\section{Quadro 2 - Projeto Pibid Diversidade por IES}

\begin{tabular}{|c|c|}
\hline IES & PROJETO \\
\hline Universidade Federal de Pernambuco & Intercultural Indígena \\
\hline Universidade Estadual da Bahia & Intercultural Indígena \\
\hline Instituto Federal da Bahia & Intercultural Indígena \\
\hline Universidade Federal do Recôncavo Baiano & Intercultural Indígena \\
\hline Universidade Regional do Cariri & Educação do Campo \\
\hline Universidade Federal do Ceará & Educação do Campo \\
\hline Universidade Federal do Piauí & Educação do Campo \\
\hline Universidade Federal de Campina Grande & Educação do Campo \\
\hline Universidade Federal do Maranhão & Educação do Campo \\
\hline Instituto Federal do Maranhão & Educação do Campo \\
\hline Universidade Tecnológica Federal do Paraná & Educação do Campo \\
\hline Universidade Estadual de Maringá & Educação do Campo \\
\hline Universidade Estadual do Oeste do Paraná & Educação do Campo \\
\hline Universidade Federal de Santa Catarina & $\begin{array}{l}\text { Intercultural Indígena } \\
\text { Educação do Campo }\end{array}$ \\
\hline Universidade Federal da Fronteira Sul & Educação do Campo \\
\hline Universidade Comunitária da Região de Chapecó & Intercultural Indígena \\
\hline $\begin{array}{l}\text { Instituto Federal de Educação, Ciência e Tecnologia do } \\
\text { Pará }\end{array}$ & Intercultural Indígena \\
\hline Universidade Federal do Pará & Educação do Campo \\
\hline Universidade Federal do Amazonas & Intercultural Indígena \\
\hline Universidade Federal de Rondônia & Intercultural Indígena \\
\hline Universidade Federal de Roraima & $\begin{array}{l}\text { Intercultural Indígena } \\
\text { Educação do Campo }\end{array}$ \\
\hline
\end{tabular}




\begin{tabular}{|l|c|}
\hline Universidade Federal de Goiás & Intercultural Indígena \\
\hline Universidade Federal de Grande Dourados & Educação do Campo \\
\hline Universidade do Estado de Mato Grosso & Intercultural Indígena \\
\hline Universidade Federal de Mato Grosso do Sul & $\begin{array}{c}\text { Intercultural Indígena } \\
\text { Educação do Campo }\end{array}$ \\
\hline Universidade de Brasília & Educação do Campo \\
\hline Universidade de Taubaté & Educação do Campo \\
\hline Universidade Federal de Minas Gerais & $\begin{array}{c}\text { Intercultural Indígena } \\
\text { Educação do Campo }\end{array}$ \\
\hline $\begin{array}{l}\text { Universidade Federal dos Vales do Jequitinhonha e } \\
\text { Mucuri }\end{array}$ & Educação do Campo \\
\hline
\end{tabular}

Fonte: Dados advindos das IES.

O quadro 2 expressa o acento aos povos do campo, apresentando-se em 19 projetos distribuídos entre as IES que compõe as cinco regiões brasileiras, tendo como auge dessa concentração as regiões nordeste e sul com sete e seis projetos, consecutivamente.

Embora a CAPES não evidencie o reconhecimento da diferença, introduzindo a possibilidade de apresentação dos sujeitos do campo, quilombolas e indígenas, anuncia com estes projetos a tentativa de caracterizar a geopolítica descolonial, tornando visível os sujeitos que permaneceram invisíveis e condenados aos padrões de dominação, inibindo o diálogo e impondo a evidência as formas de colonialidade (MALDONADO-TORRES, 2008).

Neste sentido, a CAPES através do Edital $N^{\circ} 7$ de 2018, reduziu a abrangência do processo formativo para a diferença, desconsiderando:

1) As especificidades dos cursos de licenciatura Intercultural Indígena e Educação do Campo, dada a discrepância territorial e uso da metodologia da alternância, atendendo a dinâmica de funcionamento dos cursos - PROLIND, PROCAMPO, LICEI e LECAMPO, bem como aos seus respectivos subprojetos.

2) O diálogo e articulação entre o MEC, os sistemas e as redes de ensino, as instituições educativas e as instituições formadoras (Decreto № 8.752 que dispõe sobre a Política Nacional de Formação de Professores), mantendo um processo formativo paritário através das ações de intervenção nas escolas das redes públicas - estaduais e municipais - e nos espaços educativos dos Movimentos Sociais do Campo, Indígenas, Quilombola e das cidades, dos Centros de Formação em Alternância, em atuação 
fortalecida com o que preconiza as Diretrizes Curriculares Nacionais para Educação Escolar Indígena na Educação Básica; Resolução CNE/CEB 05/2012 - Diretrizes Curriculares Nacionais para Educação Escolar Indígena na Educação Básica; Convenção 169 sobre Povos Indígenas e Tribais da Organização Internacional do Trabalho (OIT) (Decreto Presidencial $\mathrm{N}^{\circ}$ 5.051/2004 - promulga a Convenção 169 da OIT).

3) A especificidade da licenciatura Intercultural, compreendida como sendo uma formação específica para a formação de docentes indígenas e quilombolas que promova a valorização do estudo das populações tradicionais, conforme definição do Decreto $\mathrm{N}^{\circ}$ 6.040 , de 07 de fevereiro de 2007, grupos culturalmente diferenciados e que se reconhece como tais, que possuem formas próprias de organização social, que ocupam e usam territórios e recursos naturais como condição para sua reprodução cultural, social, religiosa, ancestral e econômica, utilizando conhecimentos, inovações e práticas gerados e transmitidos pela tradição.

4) As áreas de conhecimento do PIBID Diversidade, a saber: Educação do Campo; Educação do Campo - Ciências da Natureza e Matemática; Educação do Campo - Ciências Humanas e Sociais; Educação do Campo - Linguagens e Códigos; Intercultural Indígena; Intercultural Indígena - Ciências da Natureza e Matemática; Intercultural Indígena - Ciências Humanas e Sociais; Intercultural Indígena - Linguagens e Códigos; e, Interdisciplinar.

5) A docência como ação educativa e como processo pedagógico, envolvendo conhecimentos específicos que atendam os princípios e objetivos da formação, atendendo os valores éticos, políticos, culturais, científicos e estéticos inerentes ao ensinar e aprender em diálogo com as diferenças.

6) A formação educativa, contemplada, entre outros, na: (a) relação teoria-prática; (b) trabalho coletivo e intercultural; (c) compromisso social e valorização do profissional da Educação; (d) gestão democrática, conforme define a Base Nacional Comum, articulando-as com outras dimensões do processo de desenvolvimento profissional. 
A não acolhida da CAPES às demandas advindas do público do PIBID Diversidade, em particular, revelou, apesar da abertura à recepção do mesmo, o antidiálogo, alicerçado pela relação de verticalidade entre os sujeitos, na qual não há comunicação, só comunicados, caracterizando-se pela ausência dos fundamentos do diálogo, da desamorosidade, da não criticidade e da arrogância (FREIRE, 2011).

A busca por uma educação dialógica, contradiz a ideologia dominante, interferindo politicamente nas relações sociais de aprendizagem, impedindo 0 pensamento crítico,

Assim, esvai-se a o princípio da diferença e a natureza específica das condições de infraestrutura e da geopolítica do conhecimento, local e inter localmente, das comunidades indígenas, do campo e quilombolas.

\section{Breves considerações}

O PIBID ao longo de seus 11 anos (2007-2018) elaborou uma relação integradora com maior abrangência nos desdobramentos das aprendizagens dos sujeitos na relação com as IES, as escolas, o FORPIBID e as comunidades indígenas, do campo e quilombolas.

A integração entre as atividades do Ensino Básico e Superior, desencadeadas pelas coordenações institucionais do programa, junto ao conjunto dos participantes, coordenadores, supervisores, licenciandos e estudantes, alcançou desdobramentos diversos sobre e entre os sujeitos, individuais e coletivos, envolvidos. Essa materialização tem seu alcance nos espaços de atuação, explicitando o anúncio do direito de usufruírem de outras formas de legitimação dos conhecimentos, sem negar o direito público e cidadão adquirido de uma educação diferenciada aos singulares sujeitos de direito.

Em março de 2018, a Capes ao lançar o Edital № 07 do PIBID anuncia o emudecimento daqueles que se posicionam criticamente contra o retrocesso dos direitos conquistados por populações historicamente excluídas da Educação Básica e do Ensino Superior, a saber: povos do campo, comunidades quilombolas e indígenas.

As ações que protestam contra a Proposta de Emenda Constitucional PEC 241/55, que estabelece um limite para os gastos públicos, e a Medida Provisória - MB 746/2016, que trata da implementação das Escolas de Ensino Médio em Tempo Integral, evidenciam um processo de conscientização pela dignidade da vida e o respeito ao caráter político e pedagógico da Educação como um direito de todos/as e o dever do Estado. 
A criminalização dos movimentos sociais, a interrupção das lutas por direitos, a represália aos estudantes de escolas públicas em todo Brasil, que protestaram contra a PEC 241/55 são exemplos da investida governamental pela invisibilidade aos grupos sociais minoritários excluídos da sociedade brasileira.

Com o PIBID Diversidade, não poderia ser diferente. A reafirmação nos chega com a desconsideração de um edital específico ao público do PIBID Diversidade, que durante sua existência (2010-2018), contemplando 29 IES, através de 33 projetos, evidencia o conservadorismo estrutural do Estado brasileiro.

A invisibilidade desses sujeitos sociais na publicação do Edital $\mathrm{N}^{\circ} 07 \mathrm{em}$ 2018, pela CAPES, elimina o outro através do capital de autoridade, quando exclui o direito de pronunciar-se, impondo a ideologia dos iguais que não servem como farol para práticas educativas libertadoras.

A relevância social das ações educativas, ocupantes dos espaços não clássicos para o exercício do ato de ensinar-e-aprender, oxigenam e inovam os conhecimentos, ampliando seus adeptos e evitando a descontinuidade das conquistas sociais.

Nesta direção, reafirmamos a relevância da educação libertadora, crítica, política e educativa, a fim de fazer ressurgir a manutenção dos princípios democráticos e participativos, enquanto requisitos básicos para a implementação de políticas públicas educacionais para as diferenças, consoante ao direito de todos cidadãos brasileiros em acessar uma educação pública e digna de ensinagens outras que almejem um projeto de sociedade mais igualitário.

Deste modo, o FORPIBID mantêm-se como referência no fortalecimento do trabalho coletivo, respeitando os objetivos comuns de cada programa PIBID e PIBID Diversidade; bem como, os cenários limitativos e possibilitadores dos sonhos e estratégias no desenvolvimento das aprendizagens e nas incertezas da luta.

A contextualização apresentada também permitiram a construção de estratégias para o enfrentamento das lutas e a compreensão dos contextos como pontos de partida e de chegada para vivenciar a dinâmica de atividades e ações do Fórum, entre outros por se tratar de trajetórias comuns e específicas.

Por fim, o FORPIBID buscou, junto aos sujeitos envolvidos, dar visibilidade às experiências e conhecimentos no âmbito da formação docente, evidenciando novas formas de diálogo entre as IES, as escolas da Educação Básica, o Ensino Superior, os órgãos financiadores e gestores do PIBID. 


\section{REFERÊNCIAS}

BRASIL. Constituição da República Federativa do Brasil. Brasília/DF, 5 de outubro de 1988. abril de 2004.

Decreto Presidencial N 5.051, Convenção 169 da OIT, Brasília/DF, 19 de

Lei de Diretrizes e Bases da Educação Nacional, N 9.394/96,

Brasília/DF, dezembro de 1996.

Lei № 12.796, Brasília/DF, 04 de abril de 2013.

Lei № 12.796, Altera a Lei no 9.394, de 20 de dezembro de 1996, Brasília/DF, 04 de abril de 2013.

Plano Nacional de Educação para o decênio 2014-2024, Lei № 13.005, Brasília/DF, 2014.

CAPES. Edital Conjunto № 2, CAPES, SECADI-MEC, Brasília/DF, 2010.

Edital N 7, Chamada Pública para Apresentação de Propostas.

Coordenação de Aperfeiçoamento de Pessoal de Nível Superior - Programa Institucional de Bolsa de Iniciação à Docência - PIBID, CAPES: Brasília/DF, 2018.

FREIRE, Paulo. Por uma pedagogia da pergunta. $7^{\text {a }}$ Ed., Rio de Janeiro: Paz e Terra, 2011.

MALDONADO-TORRES, Nelson. A topologia do Ser e a geopolítica do conhecimento. Modernidade, império e colonialidade, Revista Crítica de Ciências Sociais, N 80, março de 2008. p. 71-114. 